\title{
Metamorphic evolution and exhumation processes of the newly discovered Xilang eclogite in Tibet—constraints from phase equilibrium modeling and Raman microspectroscopy
}

Cong Zhang ${ }^{1, *}$, Thomas Bader ${ }^{2}$, Jingsui Yang ${ }^{1}$, Herman van Roermund ${ }^{3}$

1. Key laboratory of Deep-Earth Dynamics of MNR, Institute of Geology, Chinese Academy of Geological Sciences, Beijing 100037, China.

2. School of Earth and Space Sciences, Peking University, Beijing 100087, China

3. Department of Earth Sciences, Structural Geology and Tectonics, Utrecht University, 3508 TA, Utrecht, the Netherlands

* Corresponding author email: congzhang@pku.edu.cn

\begin{abstract}
Due to the high density at mantle depths, subducted oceanic crust rarely exhumes to the surface of Earth, making it hard to acknowledge the evolution and dynamic behavior of oceanic crust. The Sumdo eclogite-bearing metamorphic belt, lying between the north and south Lhasa terranes, is a natural laboratory to study the metamorphic evolution of oceanic eclogites. For the newly discovered Xilang eclogite in the Sumdo metamorphic belt, Tibet, we combined phase equilibrium modeling with detailed petrological investigations and obtained near-peak metamorphic conditions of $539{ }^{\circ} \mathrm{C}$ at $1.84 \mathrm{GPa}$ and a fast exhumation P-T path with a steep slope, which is much lower than the eclogites in the other areas of the Sumdo metamorphic belt. Quartz inclusions sealed in garnet from high-pressure rocks are known to preserve residual pressures during fast exhumation, which can be used as an indicator of the peak metamorphic conditions of eclogites. Quartz from four different areas in the belt, including Xilang, Sumdo, Jilang, and Xindaduo, have been measured by laser Raman micro spectroscopy. Xilang eclogite preserved the highest residual pressure of $0.53 \pm$ $0.07 \mathrm{GPa}$ in the quartz stability field. A comparison of the residual pressures between eclogites from different areas reveals a positive relationship of the residual pressure and the peak metamorphic conditions for the areas with similar exhumation processes. The exhumation duration of the host rocks also controls the residual pressures, which confirmed the previous numerically modeling of the mechanical solutions of viscous relaxation in the host mineral. It indicates that the systematic investigation of residual pressures may be a new way to get geochronological information in addition to isotopic investigations.
\end{abstract}

KEY WORDS: metamorphic evolution, Sumdo metamorphic belt, Raman geobarometry, pseudosection, exhumation mechanism of oceanic crust 